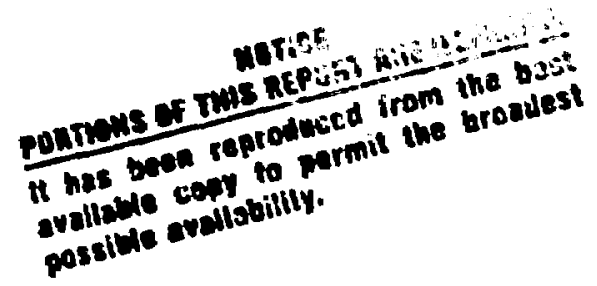

\section{UCRL, 90555}

PREPRINT

j:,$i=$

\title{
A NOVEL PROBE FOR DETERMINING THE SIZE AND POSITION OF A RELATIVISTIC \\ ELECTRON BEAM
}

T. J. Orzechowski, H. Koehler, W. Edwards

M. Nelson, B. Marshall

This paper was prepared for submittal to

SPIE 28th Annual Technical Symposium

San Diego, CA

19-24 August 1984

July 23, 1984

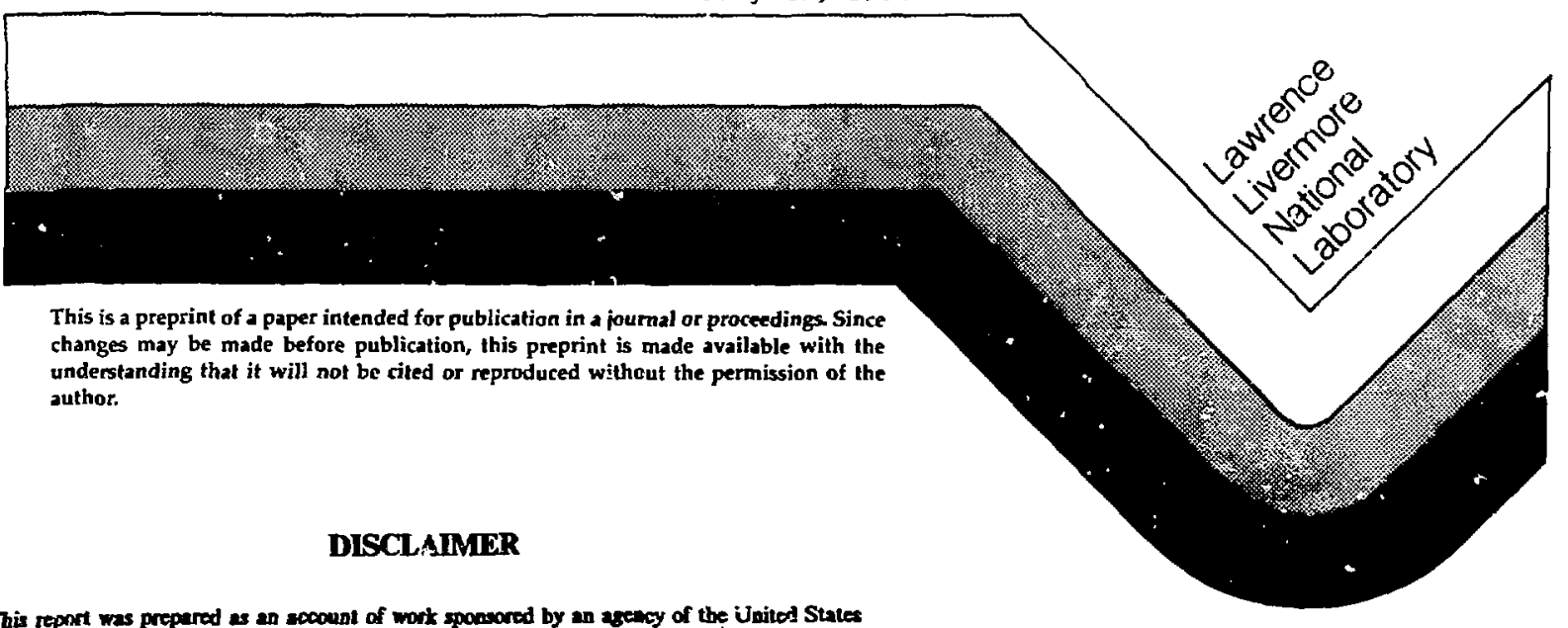

Governent Neither the Uaited States Government nor any asency thereof, nor any of their employees males any warranty, express or implied, or anomes any legal liability er responsbility for the socuracy, compietesen, or meduluces of any information, apperatus, product, or

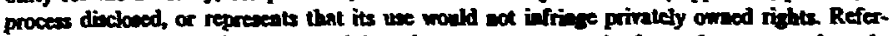

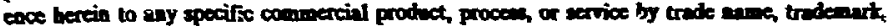

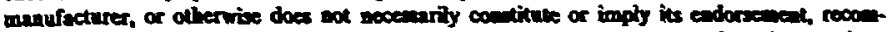

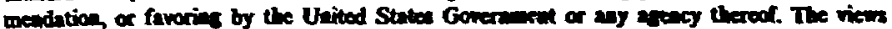

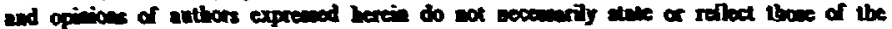

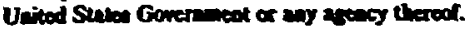




\section{DISCI.AIMIER}

This documeal was prepared as an account of work sponsored by an agency of the United States Goverament. Nejlher the Uinited Siates (iavernment nor the University of California mor any of their employees, makes any warranty, express or implied. or assumes any lefal limbility of responsibility for the accuracy, completeness, or usefulness of any information, apparstus, product, or process disclosed, or represents that its use would not iafringe privately owned rights. Reference herein to any specilic commercial products, process, or service by trade name, trademark, manufacturer, or otherwise, does not necessirily constitute or imply its endorsement, recommendation, or favoring by the $t$ inited States Government or the University of Californis. The views and opinions of authors expressed herein do not necessorily state or reflect those of the linited States Government thereof, and shall not be used for advertising or product endorsement purposes. 


\title{
A MOYEL PROBE FOR DETERMIMING THE SIZE AND POSITION
}

OF A RELATIVISTIC ELECTRON BEAM*

\author{
T. J. Orzerhowski, Helmut Koehler, H. Edwards \\ University of California, Lawrence Livermore Hational Laboratory \\ Livermore, California 94550 \\ M. Nelson, B. Marshall
}

EG\&G, Santa Barbara, P. 0. Box 98, Goleta, California 93017

July 23, 1984

\section{AB:TRACT}

In order to determine the size and position of a relativistic electron beam inside the wiggler magnetic field of a Free Electron Laser (FEL), we have developed a new probe which intercepts the electron beam on a high $Z$ target and monitors the resulting bremsstrahlung radiation. The prcbe is designed to move along the entire three meters of the wiggler. ${ }^{1}$ This FEL is designed to operate in the microwave region $(2-8 \mathrm{~mm})$ and the interaction region is an oversized waveguide with a cross section $3 \mathrm{~cm} \times 9.8 \mathrm{~cm}$. The axial probe moves inside this waveguide. The probe stops the electron beam on a Tantalum target and the resulting $x$-rays are scattered in the forward direction. A scintillator behind the bean stop reacts to the $x$-rays and emits visibie light in the region where the x-rays strike. An array of fiber optics behind the scintillator transmits the visible light to a Reticon camera system which images the visible pattern from the scintillator. Processing the optical image is done by digitizing and storing the image and/or recording the image on video tape. Resolution and performance of this probe will be discussed.

*Performed jointly under the auspices of the U.S. DOE by LLNL under iN-7405-ENG-48 and for the DOD under DARPA, ARPA Order No. 4855, Program Code No. 3B10. 


\section{A Free Electron Laser (FEL) ${ }^{1}$ experiment is now operating at the Lawrence}

Livermore Mational Laboratory. The wiggler magnetic field is plane polarized and only provides focusing in the vertical direction. Focusing in the horizontal (wiggle plane) direction is provided by quadrupoles which surround the wiggler magnets. Since the FEL is operating in the microwave frequency regime, the interaction region of the laser is an overmoded waveguide (cross-section dimensions are $3 \mathrm{~cm}$ by $10 \mathrm{~cm}$ ). The period of the wiggler field is $9.8 \mathrm{~cm}$ while the length of the interaction region is 3 meters. The wiggler magnet with horizontal focusing quadrupoles is shown ir Figure 1 . Due to the compact construction of the magnets, as well as the fact that the waveguide interaction region cannot be easily penetrated for electron beam or radiation probes, a special probe was constructed to monitor the beam size and position in the interaction region.

The electron beam used in this FEL has a beam energy of $3.5 \mathrm{MeV}$ and a current of 100 to 1000 Amp's. The pulse length of the beam is approximately $15 \mathrm{~ns}$. The FEL operates at $0.5 \mathrm{~Hz}$ (one pulse every 2 seconds). Ouring the initial experiments, we could not propagate the beam through the wiggler. Subsequent computer modeling indicated that unless the beam is properly matched into the wiggler, it will not propagate through the interaction region. Since there were no beam diagnostics once the beam entered the wiggler, it was impossible to determine where the electrons were being lost or what were the reasons for their loss. The probe developed to monitor the electron beam takes advantage of the fact that the electrons are relativistic. The electron beam strikes the Tantalum (Ta) target which is located on the face of the axial probe. This target attaches to the front of a thin-walled, stainless steel, vacuum-tight housing which contains an NE 108 
scintillator followed by a $4 \times 9$ array of fiber optics that monitor the light Emitted by te scintillator in response to the $x$-rays produced in the Ta target. 2 This detector scheme is illustrated in Figure 2. Two 3-meter long stainless steel tubes house the fibers as well as air cooling channels for the scintillator and fiber optics. An auditional 15 meters of fiber optics bring the light signals to a camera located outside the shieided accelerator wall. This camera images the $4 \times 9$ array of fiber optics onto a Reticon photodiode array camera. The output of the Reticon camera is digitized and the signal displayed on an $x y$-monitor.

The detector is iilustrated in Figure 3; Figure 4 shows the actual probe head. The probe is designed to monitor the size and position of the electron beam over the entire length of the interaction region. The face of the probe consists of a $3 \mathrm{~mm}$ thick Tantalum plate which serves as the beam stop. This Ta plate is approximately one range thick for the $3.5 \mathrm{MeV}$ electrons. ${ }^{3}$ This target is fixed onto the front of the probe housing whichcontains the scintillator and fiber optics. Since the interaction region is at vacuum $\left(10^{-5}\right.$ Torr) and the fiber optics communicate with the outside world, the interior of the housing is at atmospheric pressure. The cross-sectional area of the housing is $2.8 \mathrm{~cm}$ high and $9.8 \mathrm{~cm}$ wide. The housing makes contact with the wall of the waveguide interaction region via Copper-Beryllium finger stock which provides a return current path for the electron beam striking the probe face. The thin-walled construction of the probe housing ensures both a close coupling of the scintillator to the target and maximum area for detection (thicker walls would reduce the usable area of the scintillator which is inside the probe housing). 
A 1 m thick slab of NE10B scintillator is locaters at the front of the inside of the probe housing. A I mm gap between the irside of the front wall and the scintillator provides a path for air cooling the face of the scintillator. The fiber optics which detect the response of the scintillator are located directly behind the scintillator. The array of fiber optics is emberded in a $2.54 \mathrm{~cm}$ thick lead block. The 36 fibers are arranged in nine columns separated $9.4 \mathrm{~mm}$ apart and 4 rows separated $5 \mathrm{~mm}$ apart. The QSF-AS fibers have a core diameter of 163 microns (the glass outside diameter is 200 microns). The lead block serves to position the fibers in the array and to stop the $x$-rays that pass through the scintillator before reaching the fiber optics bundle at the back of the probe housing. The range of a $3.5 \mathrm{MeV}$ photon in lead is approximately $2 \mathrm{~cm} .{ }^{4}$

We can crudely estimate the spatial resolution of the probe as follows: an electron which is stopped in the Ta target (one range thick) emits $x$-rays in a forward cone with a half angle $1 / Y$. If this $x$-ray pattern originates at the middle of the target and propagates through the housing wall $(1 \mathrm{~mm})$, air gap $(1 \mathrm{~mm})$, and scintillator $(1 \mathrm{~mm})$, the half width of the radiation pattern will be $r \simeq d \times \tan (1 / Y)=4.5 \tan (1 / Y) \mathrm{mm}$. For $\gamma=8$, the radius of the image will be approximate $1 y 0.6 \mathrm{~mm}$. For an electron beam with a $5 \mathrm{~mm}$ radius, this resolution is quite adequate for our purpose. The fiber optics, which are close coupled to the scintillator, have a numerical aperature of 0.25 . This implies that the fiber optics can view a spot with a diameter of $0.7 \mathrm{~mm}$ at a distance of $1 \mathrm{~mm}$. Thus, the minimum spot size we should be able to resolve has a 0.9 diameter.

The fiber optics are brought out of the probe head and interaction region through a $320 \mathrm{~cm}, 1.27 \mathrm{~cm} \mathrm{0.0.} \mathrm{stainiess} \mathrm{steel} \mathrm{tube.} \mathrm{An} \mathrm{identical} \mathrm{tube} \mathrm{is}$ 
used as the input channel for the air cooling for the scintillator. The return path for the air flow is through the tube housing the fiber optics (see Figure 3). These two tubes come out of the vacuum interaction region through sliding 0-ring seals. The ends of the tubes are connected to a drive unit which moves the probe along the entire length of the interaction re: $n$. A precision potentiometer on the drive unit allows continuous mor,itoring of the probe position. The probe drive speed is adjustable but was typically set to $0.5 \mathrm{~cm} / \mathrm{sec}$ which corresponded to a probe motion of $1 \mathrm{~cm}$ between electron beam pulses.

The 36 fibers are brought out to a camera located outside the radiation shield (a distance of approximately 20 meters). The fibers are arranged in a 2-dimensional array pattern corresponding to their location inside the probe housing. This array is imaged through a cross polarizer and band pass filter onto an $18 \mathrm{~mm}$ diameter ITT Muiti channel Plate Intensifier (MCPI) using a $50 \mathrm{~mm}$ focal length, F1.4 Nikon camera lens. The cross-polarizer serves as a yariable attenuator. The optional band pass filter (20 nm band centered at $570.0 \mathrm{~nm}$ ) selects only the $576 \mathrm{~nm}$ signal from the NE108 scintillator while rejecting fluorescence at other wavelengths. The MCPI has an \$20 photocathode input and a P2OR phosphor output. 5,6 The P2OR output is used to provide a better match to the spectral sensitivity of the Silicon photodiode array of the Reticon camera. A variable width gated shutter is used on the input of the MCPI to improve the S/N ratio by collecting signals only when the beam is striking the target. Typically, a $40 \mathrm{~ns}$ gate is used and is triggered from the master-timing of the accelerator. The signal from the output of the :PI is imaged onto the photodiode array of the Reticon camera through an $18 \mathrm{~mm}$ to $10 \mathrm{~mm}$ fiber optic image reducer. 
The signal anplification due to the MCPI is approximately 300 times the system gain, which is about one. That is, without the MCPI, the loss through the system due to expanding the image and absorption in the optics is balanced by the $4 x$ increase in intensity due to the image reducer; thus, $N$ photons $/ \mathrm{cm}^{2}$ at the input results in $N$ photons $/ \mathrm{cm}^{2}$ at the diode array on the camera.

The diode array consists of $100 \times 100$ pixels located on a $0.6 \mathrm{~cm} \times 0.6 \mathrm{~cm}$ silicon wafer. This implies that there are three pixels per fiber. The camera system was calibrated with an 0ptoliner at $570 \mathrm{~nm}$. The dynamic range of $200: 1$ is limited by the Reticon camera digitizer.

The digitized output of the reticon camera is read into a Lecroy memory unit processed by an RCI TRAPIX system and displayed on a monitor. The timing and data collection scheme is illustrated in Figure 6. The digitized data collection is initiated by a trigger pulse from the master timing chain.

Figure 7 shows a typical beam image. The beam spot appears to be well centered on the probe. The beam is between .5 and $1 \mathrm{~cm}$ high and between 1 and $2 \mathrm{~cm}$ wide. The uncertainty in beam size is determined by the number of fibers illuminated and the distance between fibers. By studying the beam pattern and position as a function of probe position in the wiggler, we were able to optimize the beam matching into the wiggler as well as correct some problems associater with the wiggler magnetic field (i.e., a wiggler period was wired backwards). With proper matching, virtually all of the electron beam can be transported through the wiggler. 


\section{REFERERCES}

1. T. J. Orzechowski, M. C. Moebus, F. A. Penko, D. Prosnitz, D. Rogers, Lawrence Livermore Mational Laboratory; C. S. Chavis, K. Halbach, D. B. Hopk ins, R. H. Kuenning, A. C. Paul, A. M. Sessler, G. D. Stover, J. T. Tanabe, R. M. Yamamoto, J. S. Wurtele. Lawrence Berkeley Laboratory, "The Status of the Lawrence Berkeley Laboratory and Lawrence Livermore National Laboratory (LLNL) Free Electron Laser," Free Electron Generators of Coherent Radiation, Char les A. Brau, Stephen F. Jacobs, Marlan 0. Scully, Organizers/Editors, SPIE Volume 453, (1983).

2. H. A. Koehler, D. L. Redhead, M. Nelson, Lawrence Livermore National Laboratory Report UCRL-88497, (April 19, 1984).

3. L. Pages, E. Berte 1, H. Jaffe, and L. Sk7avenitis, "Energy Loss, Range and Bremsstrahlung Yield for $10 \mathrm{Kev}$ to $100 \mathrm{MeV}$ Electrons in Various Elements and Chemical Compounds," Atomic Data, 4, pp. 1-127 (1972).

4. R. D. Evans, The Atomic Nucleus, McGraw-Hil1 Book Co., New York, NY (1955).

5. H. A. Koehler, P. Corn ish, Microchannel Plate Intensifier Characterization, ATA Note \#192, (January 11, 1983).

6. R. Lear, "Fast Imaging Applications in the Nuclear Test Program," Nuclear Science Symposium, San Francisco, CA, October 19-21, 1983 (UCRL \#89849). 


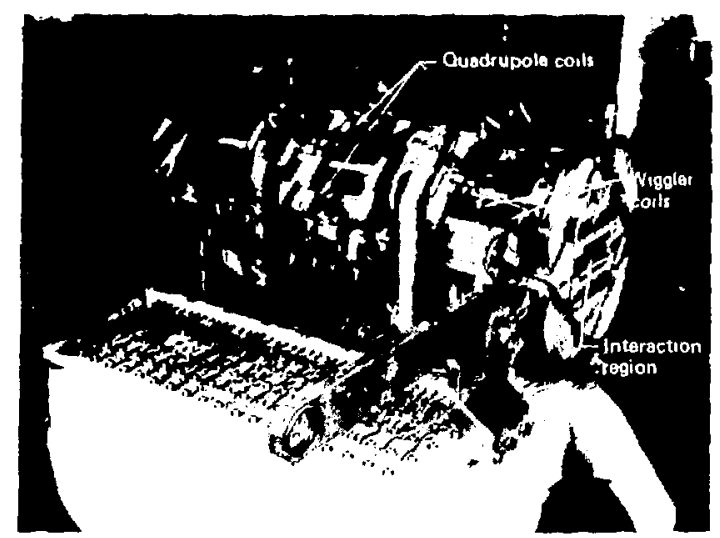

Fig. 1. One meter section of wiggler showing wiggler coils, quadrupoles, and interaction region.

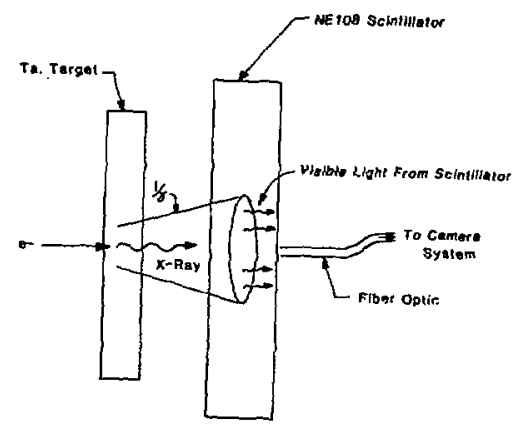

Fig. 2. Electron beam detection scheme. The beam is stopped in a Tantalum target. The resulting $x$-rays are emitted in a cone in the forward direction and strike an NE108 scintillator. The aptical emission from the scintillator is transmitted to a Reticon camera system via an optical fiber array.

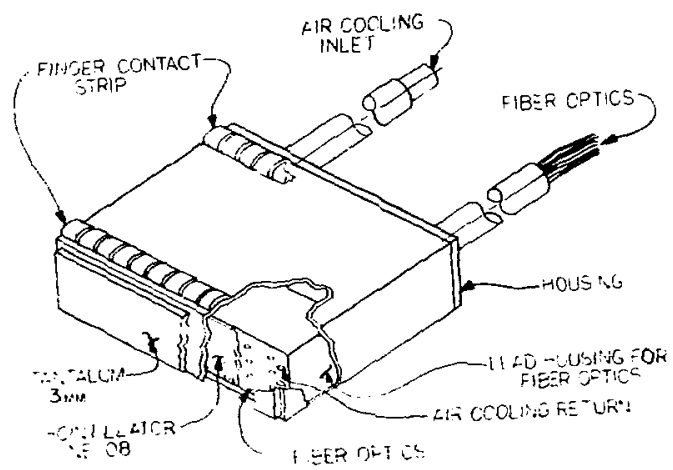

Fig. 3. Schematic of the probe head showing placement of target, scintillator and optical fiber array. 


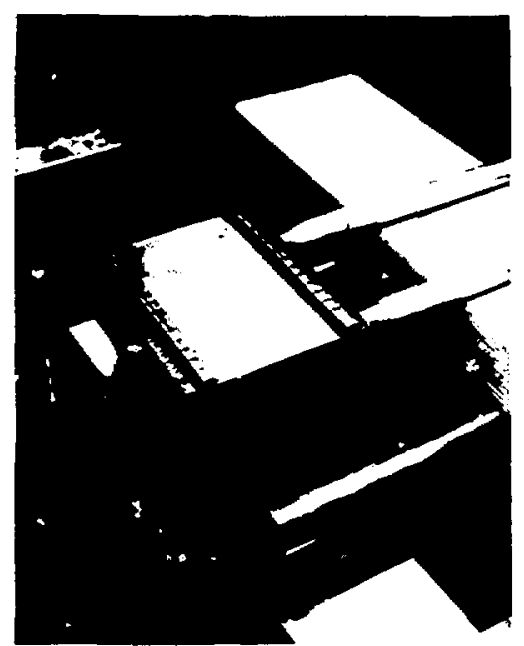

Fig. 4. Photograph of the axia? probe.

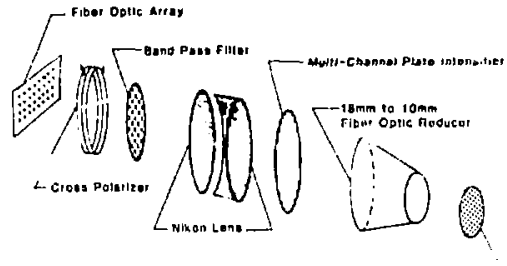

$100 \times 100$ Photodiode Arrar -

Fig. 5. Reticon camera system used to image the array of fiber optics onto the photodiode array of the camera.

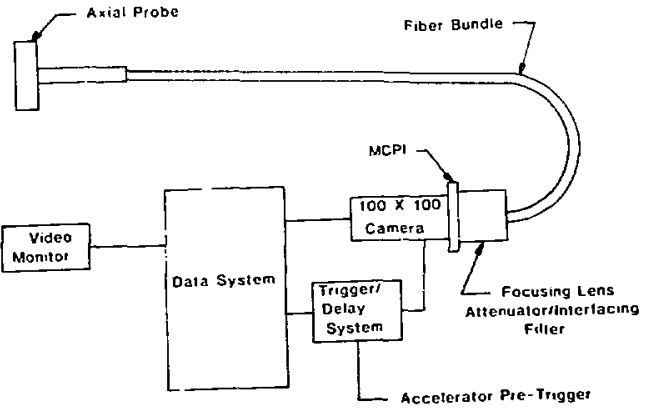

Fig. 6. Data collection and processing scheme used with the axial probe.

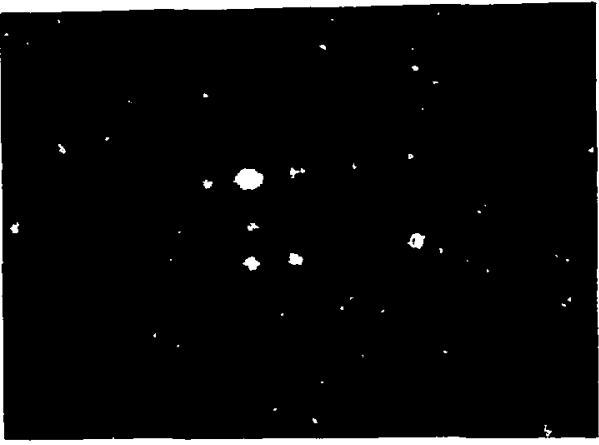

Fig. 7. Sample data showing the electron beam centered on the probe. The spacing between columns is 9.4 winile the spacing between rows is $5 \mathrm{~mm}$. 